\title{
Grid-Scale Battery Storage Frequently Asked Questions
}

\section{What is grid-scale battery storage?}

Battery storage is a technology that enables power system operators and utilities to store energy for later use. A battery energy storage system (BESS) is an electrochemical device that charges (or collects energy) from the grid or a power plant and then discharges that energy at a later time to provide electricity or other grid services when needed. Several battery chemistries are available or under investigation for grid-scale applications, including lithium-ion, lead-acid, redox flow, and molten salt (including sodium-based chemistries). ${ }^{1}$ Battery chemistries differ in key technical characteristics (see What are key characteristics of battery storage systems?), and each battery has unique advantages and disadvantages. The current market for grid-scale battery storage in the United States and globally is dominated by lithium-ion chemistries (Figure 1). Due to technological innovations and improved manufacturing capacity, lithium-ion chemistries have experienced a steep price decline of over $70 \%$ from 2010-2016, and prices are projected to decline further (Curry 2017).
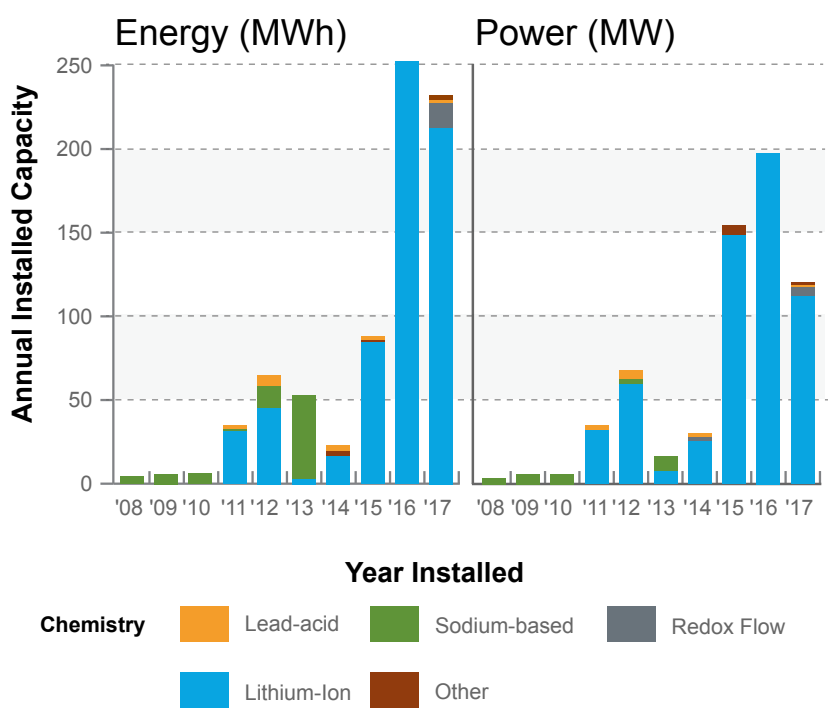

Figure 1: U.S. utility-scale battery storage capacity by chemistry (2008-2017). Data source: U.S. Energy Information Administration, Form EIA-860, Annual Electric Generator Report
Increasing needs for system flexibility, combined with rapid decreases in the costs of battery technology, have enabled BESS to play an increasing role in the power system in recent years. As prices for BESS continue to decline and the need for system flexibility increases with wind and solar deployment, more policymakers, regulators, and utilities are seeking to develop policies to jump-start BESS deployment.

\section{Is grid-scale battery storage needed for renewable energy integration?}

Battery storage is one of several technology options that can enhance power system flexibility and enable high levels of renewable energy integration. Studies and real-world experience have demonstrated that interconnected power systems can safely and reliably integrate high levels of renewable energy from variable renewable energy (VRE) sources without new energy storage resources. ${ }^{2}$ There is no rule-ofthumb for how much battery storage is needed to integrate high levels of renewable energy. Instead, the appropriate amount of grid-scale battery storage depends on system-specific characteristics, including:

- The current and planned mix of generation technologies

- Flexibility in existing generation sources

- Interconnections with neighboring power systems

- The hourly, daily, and seasonal profile of electricity demand, and

- The hourly, daily, and seasonal profile of current and planned VRE.

In many systems, battery storage may not be the most economic resource to help integrate renewable energy, and other sources of system flexibility can be explored. Additional sources of system flexibility include, among others, building additional pumped-hydro storage or transmission, increasing conventional generation flexibility, and changing operating procedures (Cochran et al. 2014).

\footnotetext{
1. For information on battery chemistries and their relative advantages, see Akhil et al. (2013) and Kim et al. (2018).

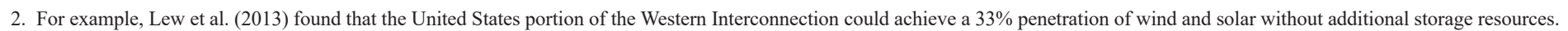

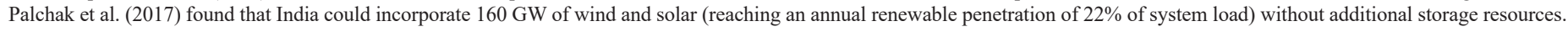




\section{What are the key characteristics of battery storage systems?}

- Rated power capacity is the total possible instantaneous discharge capability (in kilowatts [kW] or megawatts [MW]) of the BESS, or the maximum rate of discharge that the BESS can achieve, starting from a fully charged state.

- Energy capacity is the maximum amount of stored energy (in kilowatt-hours $[\mathrm{kWh}]$ or megawatt-hours [MWh])

- Storage duration is the amount of time storage can discharge at its power capacity before depleting its energy capacity. For example, a battery with $1 \mathrm{MW}$ of power capacity and $4 \mathrm{MWh}$ of usable energy capacity will have a storage duration of four hours.

- Cycle life/lifetime is the amount of time or cycles a battery storage system can provide regular charging and discharging before failure or significant degradation.

- Self-discharge occurs when the stored charge (or energy) of the battery is reduced through internal chemical reactions, or without being discharged to perform work for the grid or a customer.

Self-discharge, expressed as a percentage of charge lost over a certain period, reduces the amount of energy available for discharge and is an important parameter to consider in batteries intended for longer-duration applications.

- State of charge, expressed as a percentage, represents the battery's present level of charge and ranges from completely discharged to fully charged. The state of charge influences a battery's ability to provide energy or ancillary services to the grid at any given time.

- Round-trip efficiency, measured as a percentage, is a ratio of the energy charged to the battery to the energy discharged from the battery. It can represent the total DC-DC or AC-AC efficiency of the battery system, including losses from self-discharge and other electrical losses. Although battery manufacturers often refer to the DC-DC efficiency, AC-AC efficiency is typically more important to utilities, as they only see the battery's charging and discharging from the point of interconnection to the power system, which uses AC (Denholm 2019).

\section{What services can batteries provide?}

Arbitrage: Arbitrage involves charging the battery when energy prices are low and discharging during more expensive peak hours. For the BESS operator, this practice can provide a source of income by taking advantage of electricity prices that may vary throughout the day. One extension of the energy arbitrage service is reducing renewable energy curtailment. System operators and project developers have an interest in using as much low-cost, emissions-free renewable energy generation as possible; however, in systems with a growing share of VRE, limited flexibility of conventional generators and temporal mismatches between renewable energy supply and electricity demand (e.g., excess wind generation in the middle of the night) may require renewable generators to curtail their output. By charging the battery with low-cost energy during periods of excess renewable generation and discharging during periods of high demand, BESS can both reduce renewable energy curtailment and maximize the value of the energy developers can sell to the market. Another extension of arbitrage in power systems without electricity markets is load-leveling. With load-levelling, system operators charge batteries during periods of excess generation and discharge batteries during periods of excess demand to more efficiently coordinate the dispatch of generating resources.

Firm Capacity or Peaking Capacity: System operators must ensure they have an adequate supply of generation capacity to reliably meet demand during the highest-demand periods in a given year, or the peak demand. This peak demand is typically met with higher-cost generators, such as gas plants; however, depending on the shape of the load curve, BESS can also be used to ensure adequate peaking generation capacity. While VRE resources can also be used to meet this requirement, these resources do not typically fully count toward firm capacity, as their generation relies on the availability of fluctuating resources and may not always coincide with peak demand. But system operators can improve VRE's ability to contribute to firm capacity requirements through pairing with BESS. Pairing VRE resources with BESS can enable these resources to shift their generation to be coincident with peak demand, improving their capacity value (see text box below) and system reliability.

Firm Capacity, Capacity Credit, and Capacity Value are important concepts for understanding the potential contribution of utility-scale energy storage for meeting peak demand.

Firm Capacity (kW, MW): The amount of installed capacity that can be relied upon to meet demand during peak periods or other high-risk periods. The share of firm capacity to the total installed capacity of a generator is known as its capacity credit (\%). ${ }^{3}$

Capacity Value (\$): The monetary value of the contribution of a generator (conventional, renewable, or storage) to balancing supply and demand when generation is scarce.

Operating Reserves and Ancillary Services: To maintain reliable power system operations, generation must exactly match electricity demand at all times. There are various categories of operating reserves and ancillary services that function on different timescales, from subseconds to several hours, all of which are needed to ensure grid reliability. BESS can rapidly charge or discharge in a fraction of a second, faster 
than conventional thermal plants, making them a suitable resource for short-term reliability services, such as Primary Frequency Response (PFR) and Regulation. Appropriately sized BESS can also provide longer-duration services, such as load-following and ramping services, to ensure supply meets demand.

Transmission and Distribution Upgrade Deferrals: The electricity grid's transmission and distribution infrastructure must be sized to meet peak demand, which may only occur over a few hours of the year. When anticipated growth in peak electricity demand exceeds the existing grid's capacity, costly investments are needed to upgrade equipment and develop new infrastructure. Deploying BESS can help defer or circumvent the need for new grid investments by meeting peak demand with energy stored from lower-demand periods, thereby reducing congestion and improving overall transmission and distribution asset utilization.

Also, unlike traditional transmission or distribution investments, mobile BESS installations can be relocated to new areas when no longer needed in the original location, increasing their overall value to the grid.

Black Start: When starting up, large generators need an external source of electricity to perform key functions before they can begin generating electricity for the grid. During normal system conditions, this external

Most storage systems in the United States provide operating reserves and ancillary services. Despite this current focus, the total U.S. market for these services is limited, and utility-scale storage may begin providing more firm and peak capacity in the near future.

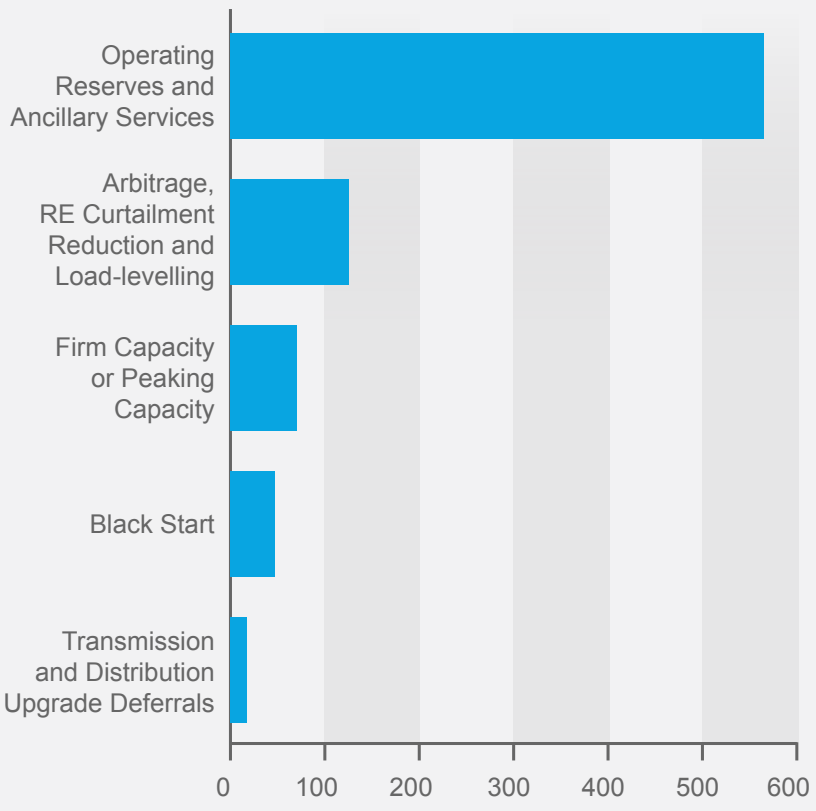

Figure 2: U.S. Utility-scale battery storage capacity by service. Data source: U.S. Energy Information Administration, Form EIA-860, Annual Electric Generator Report electricity can be provided by the grid. After a system failure, however, the grid can no longer provide this power, and generators must be started through an on-site source of electricity, such as a diesel generator, a process known as black start. An on-site BESS can also provide this service, avoiding fuel costs and emissions from conventional black-start generators. As system-wide outages are rare, an on-site BESS can provide additional services when not performing black starts.

Table 1 below summarizes the potential applications for BESS in the electricity system, as well as whether the application is currently valued in U.S. electricity markets (Denholm 2018). Figure 2 shows the cumulative installed capacity (MW) for utility-scale storage systems in the United States in 2017 by the service the systems provide.

\section{Where should batteries be located?}

Utility-scale BESS can be deployed in several locations, including: 1) in the transmission network; 2) in the distribution network near load centers; or 3) co-located with VRE generators. The siting of the BESS has important implications for the services the system can best provide, and the most appropriate location for the BESS will depend on its intended-use case.

In many cases, a BESS will be technically capable of providing a broad range of services in any of the locations described in the next section. Therefore, when siting storage, it is important to analyze the costs and benefits of multiple locations to determine the optimal siting to meet system needs. Considering all combinations of services the BESS can provide at each potential site will provide a better understanding of the expected revenue streams (see What is value-stacking?) and impact on the grid.

\section{In the Transmission Network}

BESS interconnected to the transmission system can provide a broad range of ancillary and transmission-related services. These systems can be deployed to replace or defer investments of peaking capacity, provide operating reserves to help respond to changes in generation and demand, or they can be used to defer transmission system upgrades in regions experiencing congestion from load or generation growth. Figure 3 below shows the configuration of a utility-scale storage system interconnected at the transmission substation level.

\section{In the Distribution Network Near Load Centers}

Storage systems located in the distribution network can provide all of the services as transmission-sited storage, in addition to several services related to congestion and power quality issues. In many areas, it may be difficult to site a conventional generator near load in order to provide peaking capacity, due to concerns about emissions or land use. Due to their lack of local emissions and their scalable nature, BESS systems can be co-located near load with fewer siting challenges than conventional generation. Placing storage near load can reduce transmission and distribution losses and relieve congestion, helping defer transmission and distribution upgrades. Distribution-level BESS systems can also provide local power quality services and support improved resilience during extreme weather events. 
Table 1: Applications of Utility-Scale Energy Storage

\begin{tabular}{|c|c|c|c|}
\hline Application & Description & $\begin{array}{l}\text { Duration of Service } \\
\text { Provision }\end{array}$ & $\begin{array}{l}\text { Typically Valued in U.S. Electricity } \\
\text { Markets? }\end{array}$ \\
\hline Arbitrage & $\begin{array}{l}\text { Purchasing low-cost off-peak energy } \\
\text { and selling it during periods of high } \\
\text { prices. }\end{array}$ & Hours & Yes \\
\hline Firm Capacity & $\begin{array}{l}\text { Provide reliable capacity to meet peak } \\
\text { system demand. }\end{array}$ & $4+$ hours & $\begin{array}{l}\text { Yes, via scarcity pricing and capacity } \\
\text { markets, or through resource adequacy } \\
\text { payments. }\end{array}$ \\
\hline
\end{tabular}

\section{Operating Reserves \\ - Primary Frequency Response}

- Regulation

- Contingency Spinning

- Replacement/ Supplemental

- Ramping/Load Following

Transmission and Distribution

Replacement and

Deferral
Very fast response to unpredictable variations in demand and generation.

Fast response to random, unpredictable variations in demand and generation.

Fast response to a contingency such as a generator failure.

Units brought online to replace spinning units.

Follow longer-term (hourly) changes in electricity demand.

\section{Seconds}

15 minutes to 1 hour

Yes

30 minutes to 2

hours

Hours

30 minutes to hours

Hours

Reduce loading on T\&D system during peak times.
Yes, but only in a limited number of markets.

\section{Yes}

Yes

Yes, but values are very low.

Yes, but only in a limited number of markets.
Black-Start
Units brought online to start system after a system-wide failure (blackout).
Hours

No, typically compensated through cost-of-service mechanisms.

\section{Co-Located with VRE Generators}

Renewable resources that are located far from load centers may require transmission investments to deliver power to where it is needed. Given the variable nature of VRE resources, the transmission capacity used to deliver the power may be underutilized for large portions of the year. A BESS can reduce the transmission capacity needed to integrate these resources and increase the utilization of the remaining capacity by using storage to charge excess generation during periods of high resource availability and discharge during periods of low resource availability. The same BESS can be used to reduce the curtailment of VRE generation, either due to transmission congestion or a lack of adequate demand, as well as provide a broad range of ancillary services.

\section{What is value-stacking? What are some examples of value-stacking opportunities and challenges?}

BESS can maximize their value to the grid and project developers by providing multiple system services. As some services are rarely called for (i.e., black start) or used infrequently in a given hour (i.e., spinning reserves), designing a BESS to provide multiple services enables a higher overall battery utilization. This multi-use approach to BESS is known as value-stacking. For example, a BESS project can help defer the need for new transmission by meeting a portion of the peak demand with stored energy during a select few hours in the year. When not meeting peak demand, the BESS can earn revenue by providing operating reserve services for the transmission system operator. 


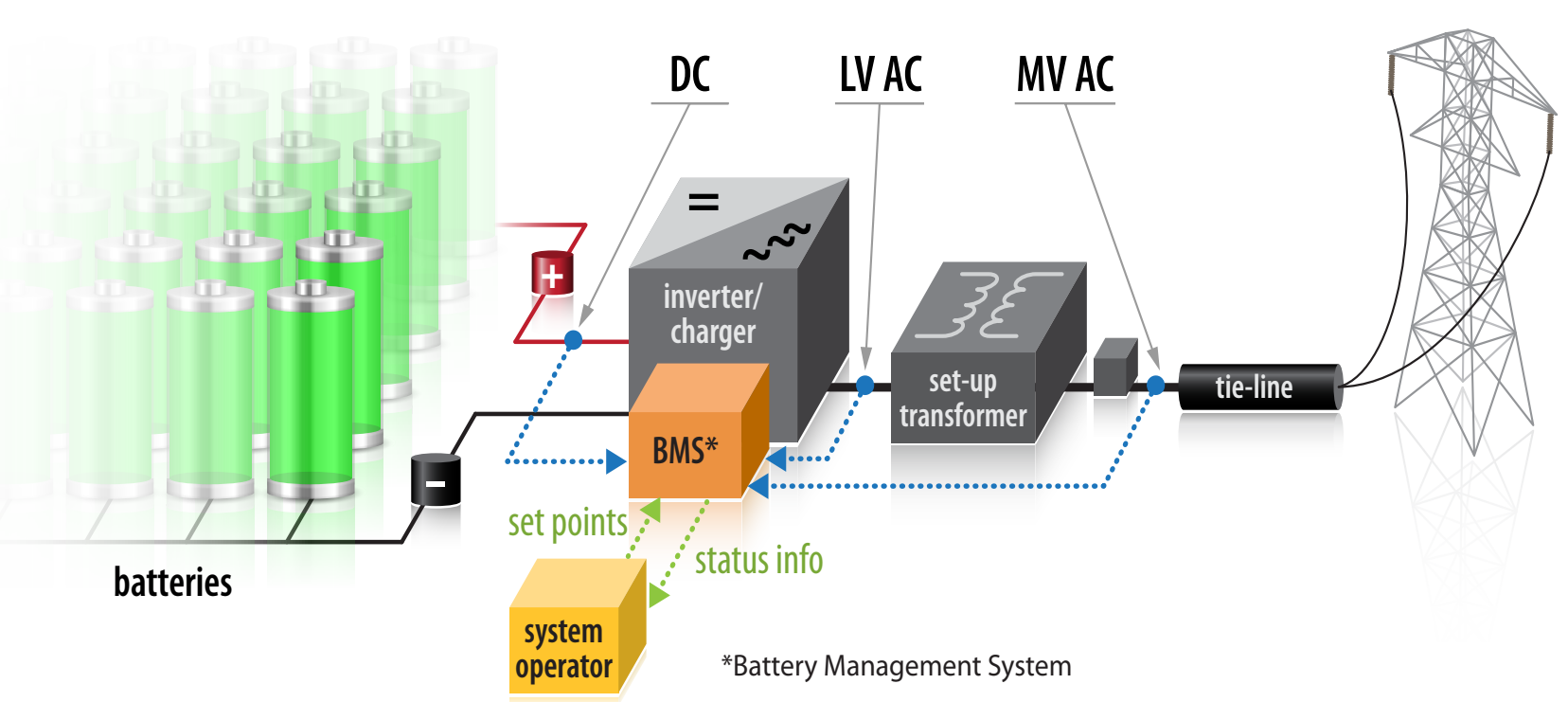

Figure 3: Key components of BESS interconnected at the transmission substation level. LV AC represents a low-voltage AC connection, while MV AC represents a medium-voltage AC connection. ${ }^{4}$ Source: Denholm (2019)

Some system services may be mutually exclusive depending on the BESS design (e.g., a short duration storage device used to supply regulating reserves would have limited value for deferring transmission or distribution upgrades). Even if a BESS is technically capable of providing multiple services, the additional cycling of the battery (charging and discharging) may degrade the battery and shorten its lifetime and economic viability. Finally, a BESS can only provide a limited duration of any set of services before it runs out of charge, which means batteries must prioritize the services they provide.

Regulators have a variety of options to enable BESS to maximize its economic potential through value-stacking. For example, the California Public Utilities Commission (CPUC) developed categories of services BESS can provide based on their importance for reliability and location on the grid, as well as 12 rules for utilities when procuring services from BESS (CPUC 2018). The CPUC rules:

- Dictate that BESS projects can only provide services at the voltage level to which they are interconnected or higher, but not lower ${ }^{5}$;

- Prioritize reliability services over non-reliability services and ensure storage cannot contract for additional services that would interfere with any obligation to provide reliability services;

- Require that a BESS project comply with all performance and availability requirements for services it provides and that noncompliance penalties be communicated in advance;

- Require that a BESS project inform the utility of any services it currently provides or intends to provide; and

- Take measures to prevent double compensation to BESS projects for services provided.
These CPUC rules are just one example of how regulators can help ensure BESS projects can select the most cost-effective combinations of services to provide without negatively impacting the reliability of the grid.

\section{How are BESS operators compensated?}

BESS operators can be compensated in several different ways, including in the wholesale energy market, through bilateral contracts, or directly by the utility through a cost-of-service mechanism. In a wholesale energy market, the BESS operator submits a bid for a specific service, such as operating reserves, to the market operator, who then arranges the valid bids in a least-cost fashion and selects as many bids as necessary to meet the system's demands. If the BESS operator's bid is selected and the BESS provides the service, the operator will receive compensation equal to the market price. This process ensures transparent prices and technology-agnostic consideration; however, many services are currently not available in the market, such as black start or transmission and distribution upgrade deferrals. Alternatively, BESS operators can enter into bilateral contracts for services directly with energy consumers, or entities which procure energy for end-consumers. This process does not ensure transparency and contracts can differ widely in both prices and terms. Finally, some BESS are owned directly by the utilities to whom they provide services, such as upgrade deferrals. In these cost-of-service cases, the utility pays the BESS operator at the predetermined price and recovers the payments through retail electricity rates. In some jurisdictions, however, BESS may be prevented from extracting revenues through both wholesale markets and cost-of-service agreements (Bhatnagar et al. 2013).

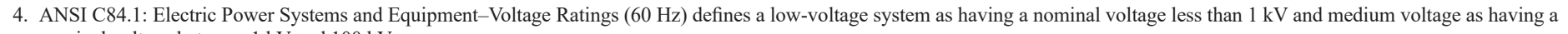
nominal voltage between $1 \mathrm{kV}$ and $100 \mathrm{kV}$.

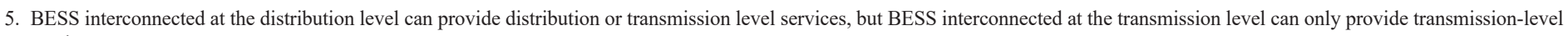
services. 


\section{How does the value of batteries change with renewable energy deployment and increased VRE penetration?}

The amount of renewable energy on the grid can influence the value and types of the services provided by a BESS. Increased levels of renewable energy may increase the need for frequency control services to manage increased variability and uncertainty in the power system. Increased levels of VRE penetration can also change the shape of the net load, or the load minus the VRE generation, influencing BESS projects that provide load following, arbitrage, peaking capacity, or similar services.

Models of the California system have shown a strong relationship between solar PV deployment and BESS' ability to replace conventional peaking capacity, also known as the BESS capacity credit (Denholm and Margolis 2018). As the shape of the load curve affects the ability of storage to provide peaking capacity, resources such as PV that cause load peaks to be shorter will enable shorter duration batteries, which are less expensive, to displace conventional peaking capacity.

Initially, low levels of PV penetration may flatten the load curve, reducing BESS' ability to cost-effectively offset the need for conventional peaking plants. ${ }^{6}$ At higher levels of solar PV penetration, however, the net load curve becomes peakier, increasing the ability and value of BESS to reduce peak demand. Figure 4 illustrates how increasing levels of PV generation change the shape of the net load, causing it to become peakier. The shaded areas above and under the net load curves indicate BESS charging and discharging, while the text boxes show the amount of net load peak reduction (MW) and the total amount of energy met by BESS during the net load peak (MWh).

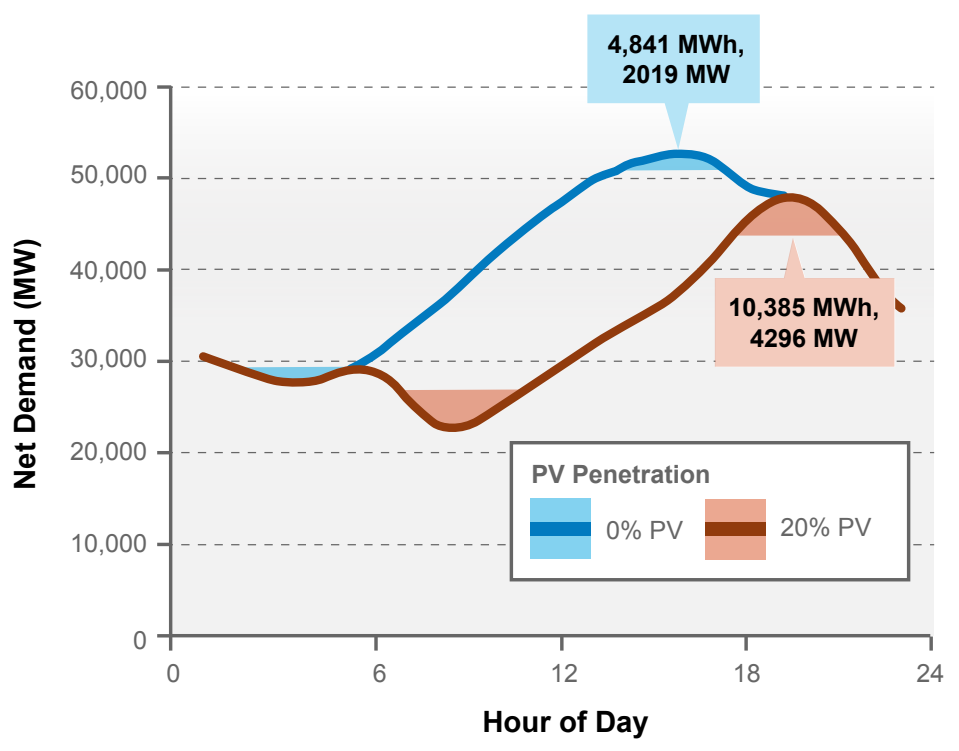

Figure 4: Change in California net load shape due to PV. Adapted from Denholm and Margolis (2018)

\section{What are the key barriers to BESS deployment?}

Barriers to energy storage deployment can be broadly grouped into three different categories: regulatory barriers, market barriers, and data and analysis capabilities.

\section{Regulatory Barriers}

- Lack of rules and regulations to clarify the role of BESS. Although storage may be technically able to provide essential grid services, if no regulations or guidelines explicitly state that storage can provide these services, utilities and market operators may be unwilling to procure services from BESS. Furthermore, without a guarantee that services provided by a BESS project will be compensated, storage developers and financing institutions may be unwilling to make the necessary capital investments. Federal Energy Regulatory Commission (FERC) Order 841 addressed this issue in U.S. wholesale markets and directed market operators to develop rules governing storage's participation in energy, capacity, and ancillary service markets. Among other requirements, the rules must ensure open and equal access to the market for storage systems, taking into consideration their unique operating and technical characteristics (FERC 2018).

\section{- Restrictions or lack of clarity around if and how storage} can be used across generation, transmission, and distribution roles. The variety of different services storage can provide often cuts across multiple markets and compensation sources. For instance, frequency regulation may be compensated in a wholesale market, but transmission or distribution investment deferrals may be compensated as a cost of service by the utility or system operator. In some jurisdictions, providing services across different compensation sources is restricted by regulation. Limiting the services batteries can provide based on where the service is provided or how it is compensated can influence how often they are utilized and whether they remain an economic investment (Bhatnagar 2013).

\section{Market Barriers}

- Lack of markets for system services. A lack of markets for services that batteries are uniquely suited to provide can make it difficult for developers to include them as potential sources of income when making a business case, deterring investment. For example, in most U.S. Independent System Operator (ISO) markets, generators are currently expected to provide inertial and governor response during frequency excursions without market compensation. Although BESS can provide the same services, currently there is no way for BESS to seek market compensation for doing so. Furthermore, the price formation for a service may have evolved for conventional generators, meaning the presence 
of batteries in the market could distort prices, affecting storage systems and conventional generators alike (Bhatnagar 2013).

\section{- Lack of discernment in quality and quantity of services} procured. For some services, such as frequency regulation, the speed and accuracy of the response is correlated to its overall value to the system. Battery systems can provide certain services much faster and more accurately than conventional resources, which may not be reflected in compensation for the service. Markets can provide fair compensation to BESS by aligning compensation schemes with the quality of service provided, as is mandated by FERC Order 755, which requires compensation for frequency regulation that reflects "the inherently greater amount of frequency regulation service being provided by faster-ramping resources" (FERC 2011). Similarly, BESS can be uniquely suited to provide up- or down-regulation, given their larger operating range over which to provide regulating reserves (due to their lack of a minimum stable level and ability to provide up- and down-regulation in excess of their nameplate capacity, based on whether they are charging or discharging) (Denholm 2019). These unique features of BESS are not necessarily reflected in the procurement requirements and compensation of such services, diminishing BESS' economic viability.

\section{Data and Analysis Capabilities}

Battery storage systems are an emerging technology that exhibit more risk for investors than conventional generator investments. These risks include the technical aspects of battery storage systems, which may be less understood by stakeholders and are changing faster than for other technologies, as well as potential policy changes that may impact incentives for battery deployment. Given the relatively recent and limited deployment of BESS, many stakeholders may also be unaware of the full capabilities of storage, including the ability of a BESS to provide multiple services at both the distribution and transmission level. At the same time, traditional analysis tools used by utilities may be inadequate to fully capture the value of BESS. For example, production cost models typically operate at an hourly resolution, which does not capture the value of BESS' fast-ramping capabilities. The gaps in data and analysis capabilities and lack of adequate tools can deter investments and prevent battery storage from being considered for services that can be provided by better understood conventional generators (Bhatnagar et al. 2013).

\section{What are some real-world examples of batteries providing services and value- stacking?}

There are several deployments of BESS for large-scale grid applications. One example is the Hornsdale Power Reserve, a $100 \mathrm{MW} / 129 \mathrm{MWh}$ lithium-ion battery installation, the largest lithium-ion BESS in the world, which has been in operation in South Australia since December 2017. The Hornsdale Power Reserve provides two distinct services: 1) energy arbitrage; and 2) contingency spinning reserve. The BESS can bid $30 \mathrm{MW}$ and $119 \mathrm{MWh}$ of its capacity directly into the market for energy arbitrage, while the rest is withheld for maintaining grid frequency during unexpected outages until other, slower generators can be brought online (AEMO 2018). In 2017, after a large coal plant tripped offline unexpectedly, the Hornsdale Power reserve was able to inject several megawatts of power into the grid within milliseconds, arresting the fall in grid frequency until a gas generator could respond. By arresting the fall in frequency, the BESS was able to prevent a likely cascading blackout.

Another example of value-stacking with grid-scale BESS is the Green Mountain Power project in Vermont. This 4 MW lithium-ion project began operation in September 2015 and is paired with a 2 MW solar installation. The installation provides two primary functions: 1) backup power and micro-grid capabilities; and 2) demand charge reductions. The solar-plus-storage system enables the utility to create a micro-grid, which provides power to a critical facility even when the rest of the grid is down. The utility operating the BESS also uses it to reduce two demand charges: an annual charge for the regional capacity market and a monthly charge for the use of transmission lines. Sandia National Laboratories estimated that reducing the annual demand charge for a single year saved the utility over $\$ 200,000$ (Schoenung 2017).

\section{References}

AEMO (Australian Energy Market Operator). Hornsdale Wind Farm 2 FCAS Trial. Knowledge Sharing Paper. Melbourne, Australia: AEMO. https://www.aemo.com.au/-/media/Files/Electricity/NEM/StrategicPartnerships/2018/HWF2-FCAS-trial-paper.pdf.

Akhil, Abbas, Georgianne Huff, Aileen Currier, Benjamin Kaun, Dan Rastler, Stella Bingquing Chen, Andrew Cotter, et al. Electricity Storage Handbook. SAND2013-5131. DOE, EPRI, NRECA. July 2013. https:// www.sandia.gov/ess-ssl/lab pubs/doeepri-electricity-storage-handbook/.

Bhatnagar, Dhruv, Aileen Currier, Jacquelynne Hernandez, Ookie Ma, and Kirby Brendan. Market and Policy Barriers to Energy Storage Deployment. SAND2013-7606. Albuquerque, NM: Sandia National Laboratories. September 2013. https://www.sandia.gov/ess-ss1/publications/SAND2013-7606.pdf.

Cochran, Jaquelin, Mackay Miller, Owen Zinaman, Michael Milligan, Doug Arent, Bryan Palmintier, Mark O'Malley, et al. "Flexibility in 21st Century Power Systems.” NREL/TP-6A20-61721. 21st Century Power Partnership. Golden, CO: NREL. May 2014. https://www.nrel.gov/docs/ fy14osti/61721.pdf.

CPUC (California Public Utilities Commission). Decision on Multiple-Use Application Issues. Rulemaking 15-03-011. January 17, 2018. http://docs.cpuc.ca.gov/PublishedDocs/Published/G000/M206/ K462/206462341.PDF.

Curry, Claire. "Lithium-Ion Battery Costs and Market." Market Report. Bloomberg New Energy Finance. July 5, 2017. https://data.bloomberglp. com/bnef/sites/14/2017/07/BNEF-Lithium-ion-battery-costs-andmarket.pdf. 
Denholm, Paul. "Greening the Grid: Utility-Scale Battery Storage.” Webinar. Clean Energy Solutions Center. February 28, 2019. https://cleanenergysolutions.org/training/ greening-grid-utility-scale-battery-storage.

Denholm, Paul. "Batteries and Storage: Truly a Game Changer?" presented at the JISEA 2018 Annual Meeting in Golden, CO. April 4, 2018. https://www.jisea.org/assets/pdfs/denholm-jisea-2018.pdf.

Denholm, Paul, and Robert Margolis. The Potential for Energy Storage to Provide Peaking Capacity in California under Increased Penetration of Solar Photovoltaics. NREL/TP-6A20-70905. Golden, CO: NREL. March 2018. https://www.nrel.gov/docs/fy18osti/70905.pdf.

FERC. Electric Storage Participation in Markets Operated by Regional Transmission Organizations and Independent System Operators. Order No. 841. Issued February 15, 2018. https:/www.ferc.gov/whats-new/ comm-meet/2018/021518/E-1.pdf.

FERC. Frequency Regulation Compensation in the Organized Wholesale Power Markets. Order No. 755. Issued October 20, 2011. https://www. ferc.gov/whats-new/comm-meet/2011/102011/E-28.pdf.

Kim, Dae Kyeong, Susumu Yoneoka, Ali Zain Banatwala, and Yu-Tack Kim. Handbook on Battery Energy Storage System. Manila, Philippines: Asian Development Bank. December 2018. https://www.adb.org/ publications/battery-energy-storage-system-handbook.
Lew, D., G. Brinkman, E. Ibanez, A. Florita, M. Heaney, B.-M. Hodge, M. Hummon, et al. The Western Wind and Solar Integration Study Phase 2. NREL/TP-5500-55588. Golden, CO: NREL. September 2013. https:// www.nrel.gov/docs/fy13osti/55588.pdf.

Mills, Andrew, and Ryan Wiser. Changes in the Economic Value of Variable Generation at High Penetration Levels: A Pilot Case Study of California. LBNL-5445E. Berkeley, CA: Lawrence Berkeley National Laboratory. June 2012. https://emp.lbl.gov/sites/all/files/lbnl-5445e.pdf.

Palchak, David, Jaquelin Cochran, Ali Ehlen, Brendan McBennett, Michael Milligan, Ilya Chernyakhovskiy, Ranjit Deshmukh, et al. Pathways to Integrate 175 Gigawatts of Renewable Energy into India's Electric Grid, Vol. I-National Study. Golden, CO: NREL. June 2017. https://www.nrel.gov/docs/fy17osti/68530.pdf.

Schoenung, Susan, Raymond H. Byrne, Todd Olinsky-Paul, and Daniel R. Borneo. Green Mountain Power (GMP): Significant Revenues from Energy Storage. Albuquerque, NM: Sandia National Laboratories. May 2017. https://www.sandia.gov/ess-ssl/publications/SAND2017-6164.pdf.

Written by Thomas Bowen, Ilya Chernyakhovskiy, Paul Denholm, National Renewable Energy Laboratory

\section{www.greeningthegrid.org | www.nrel.gov/usaid-partnership}

Jennifer E. Leisch, Ph.D.

USAID-NREL Partnership Manager U.S. Agency for International Development Tel: +1-303-913-0103 | Email: jleisch@usaid.gov

\section{Ilya Chernyakhovskiy}

Energy Analyst

National Renewable Energy Laboratory

Tel: +1-303-275-4306

Email: ilya.chernyakhovskiy@nrel.gov

This work was authored, in part, by the National Renewable Energy Laboratory (NREL), operated by Alliance for Sustainable Energy, LLC, for the U.S. Department of Energy (DOE) unde Contract No. DE-AC36-08GO28308. Funding provided by th United States Agency for International Development (USAID) under Contract No. IAG-17-2050. The views expressed in this report do not necessarily represent the views of the DOE or the U.S. Government, or any agency thereof, including USAID.

NREL/TP-6A20-74426 | September 2019

NREL prints on paper that contains recycled content.

The Grid Integration Toolkit provides state-of-the-art resources to assist developing countries in integrating variable renewable energy into their power grids. Greening the Grid is supported by the U.S. Agency for International Development.

The USAID-NREL Partnership addresses critical challenges to scaling up advanced energy systems through global tools and technical assistance, including the Renewable Energy Data Explorer, Greening the Grid, the International Jobs and Economic Development Impacts tool, and the Resilient Energy Platform. More information can be found at: www.nrel.gov/usaid-partnership.

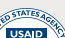

USAID

FROM THE AMERICAN PEOPLE

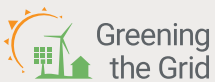

the Grid
TNREL

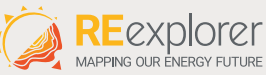

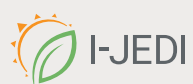

Resilient Energy
Platform 